\title{
Management of esophageal anastomotic leaks, perforations, and fistulae with self-expanding plastic stents
}

\author{
Yiyang Dai, MD, ${ }^{\mathrm{a}}$ Sascha S. Chopra, $\mathrm{MD},{ }^{\mathrm{b}}$ Sören Kneif, $\mathrm{PhD},{ }^{\mathrm{a}}$ and Michael Hünerbein, $\mathrm{MD}, \mathrm{PhD}{ }^{\mathrm{a}}$
}

Objective: Esophageal anastomotic leaks, perforations, and fistulae are associated with considerable morbidity and mortality. The aim of the present study was to assess the efficacy of self-expanding plastic stents in the treatment of esophageal leaks.

\begin{abstract}
Methods: From 2001 to 2009, 41 patients with postoperative anastomotic leaks ( $\mathrm{n}=30$ ), esophageal perforations $(n=6)$, or fistulae $(n=5)$ were treated by endoscopic insertion of self-expanding plastic stents. The clinical outcome of the patients was analyzed, including leak healing, morbidity, and mortality.

Results: Self-expanding plastic stents were successfully inserted in all 41 patients without procedure-related complications. Non-ventilated patients received oral feeding an average of 3.9 days after stent placement. Complete leak healing was obtained in 27 of 30 patients $(90 \%)$ with anastomotic leaks and 5 patients $(83 \%)$ with perforation. Sealing of fistulae by the stents was achieved in all 5 patients, and closure of the fistula was observed in 2 patients $(40 \%)$. The mean healing time was 30 days for anastomotic leaks, 15 days for esophageal perforations, and 16 days for fistulae. Stent migration occurred in 14 cases, but endoscopic reintervention and new stent placement were successful in all cases. In-hospital mortality after treatment of esophageal leaks with stents was $10 \%$.
\end{abstract}

Conclusions: In combination with effective interventional or surgical drainage, stenting is a viable option for the treatment of esophageal anastomotic leaks and perforations, but the success in tracheoesophageal fistula is limited. (J Thorac Cardiovasc Surg 2011;141:1213-7)

Through advances in surgical technique and adjuvant treatment, the prognostic outcome of esophageal cancer has improved, but anastomotic leaks after gastroesophageal resections for cancer are still a therapeutic problem. ${ }^{1-3}$ Spontaneous ruptures or esophageal perforations after endoscopic procedures are also potentially life-threatening events. The most effective way to manage these complications remains controversial. In the past, aggressive surgical reexploration and conservative treatment with additional drainage, total parenteral nutrition, nasogastric decompression, and broad-spectrum antibiotics have been associated with considerable mortality rates $(20 \%-40 \%)$, extensive intensive care unit (ICU) stay, and lengthy hospitalization of patients. ${ }^{4-6}$ Modern surgical management of esophageal leaks with early reoperation and primary anastomotic repair and reinforcement of the anastomosis with muscle flaps results in significantly lower mortality rates. ${ }^{7,8}$ Endoscopic placement of self-expanding metal stents (SEMS) has been

\footnotetext{
From the Department of Surgery and Surgical Oncology, ${ }^{a}$ Helios Hospital, Berlin, Germany; and Department of General, Visceral and Transplantation Surgery, ${ }^{\mathrm{b}}$ Charite Campus Virchow Hospital, University of Medicine, Berlin, Germany. Disclosures: Authors have nothing to disclose with regard to commercial support. Received for publication April 24, 2010; revisions received June 29, 2010; accepted for publication July 11, 2010; available ahead of print Dec 17, 2010.

Address for reprints: Michael Hünerbein, MD, PhD, Department of Surgery and Surgical Oncology, Helios Hospital Berlin, 13122 Berlin, Germany (E-mail: michael. huenerbein@helios-kliniken.de).

$0022-5223 / \$ 36.00$

Copyright (c) 2011 by The American Association for Thoracic Surgery doi:10.1016/j.jtcvs.2010.07.096
}

successfully used for definitive palliative treatment of tracheoesophageal fistulae caused by advanced mediastinal malignancy or radiochemotherapy for esophageal cancer., ${ }^{9,10}$ However, there is only limited experience with temporary stenting for the treatment of benign esophageal leaks, such as anastomotic leakage and perforation.

This study evaluated the efficacy of self-expanding plastic stents (SEPS) for the treatment of esophageal anastomotic leaks, esophageal perforations, and fistulae in a group of 41 patients.

\section{MATERIALS AND METHODS \\ Patients}

From 2001 to 2009 , SEPS were used in 41 patients for the treatment of postoperative esophageal anastomotic leaks, esophageal perforations, or tracheoesophageal or mediastinal fistulae. This analysis includes $30 \mathrm{pa}-$ tients from our hospital and 11 patients who were transferred from other institutions. All leaks were diagnosed by esophagogastroscopy and a contrast study. Indication for stenting was limited to patients with leaks involving less than $30 \%$ of the esophageal circumference and without extensive necrosis of the gastric conduit. Institutional review board approval was not necessary because esophageal stenting was considered as a routine procedure that was added to conservative treatment of esophageal leaks. There were 32 male patients and 9 female patients with a mean age of 63 years (range, 49-90 years). Postoperative anastomotic leaks occurred in 30 patients after abdomino-thoracic esophagectomy with an esophagogastric $(\mathrm{n}=18)$ or esophago-colonic anastomosis $(\mathrm{n}=1)$, transhiatal resection with an esophagogastrostomy $(n=3)$, gastrectomy with esophagojejunostomy in the lower mediastinum $(n=8)$, or resection of a diverticulum of the esophagus $(n=1)$. Three patients had a cervical leak, and 27 patients had a thoracic leak. The interval between surgery and leak detection ranged from 1 to 33 days (mean, 7.6 days). Esophageal perforations were observed 


\author{
Abbreviations and Acronyms \\ $\mathrm{CT}=$ computed tomography \\ $\mathrm{ICU}=$ intensive care unit \\ SEMS $=$ self-expanding metal stent \\ SEPS $=$ self-expanding plastic stent
}

in 6 patients after dilatation of malignant $(\mathrm{n}=3)$ or benign stenoses $(\mathrm{n}=2)$ and as the result of vomiting (Boerhaave's syndrome) in 1 patient. Tracheoesophageal fistulae occurred in 3 patients after radiochemotherapy of advanced esophageal cancer, but there was also 1 case with postoperative anastomotic leakage. An esophago-pleural fistula after migration of a gastric band and repeated surgery developed in 1 patient. The detailed clinicopathologic data of the patients are shown in Table 1.

\section{Stenting}

All patients were treated by insertion of SEPS (Polyflex; Boston Scientific, Natick, Mass). The Polyflex stent consists of an integral polyester braid that is completely covered with a silicone membrane (proximal diameter, $25 \mathrm{~mm}$; body diameter, $21 \mathrm{~mm}$; length, $12 / 15 \mathrm{~cm}$ ). Only large stents were used because smaller sizes have a higher tendency to migrate. Usually the stent was placed immediately after the diagnosis of a leak was made by endoscopy, but there was some delay in patients who were transferred from other institutions. The mean interval from diagnosis of the leak to stent placement was 2.7 days for anastomotic leaks, 3.2 days for esophageal perforations, and 2.2 days for esophageal fistulae. The stent was placed immediately during index endoscopy in 25 patients, within 24 hours in 10 patients, and after more than 24 hours in 6 patients. Three patients were initially treated with a covered SEMS before the plastic stent was implanted. Stent placement was performed under combined endoscopic and fluoroscopic control. The details have been described. ${ }^{11}$ Briefly, all patients received intravenous conscious sedation with 3 to $5 \mathrm{mg}$ midazolam. By using a Seldinger technique, the stent was inserted into the esophagus with at least a 3- to 4-cm overlap proximal and distal to the leak. Correct placement of the stent and successful leak occlusion were confirmed by endoscopy and contrast-enhanced fluoroscopy with a water-soluble contrast agent (Figure 1). Oral intake was started with clear fluids the day after stent implantation. If that was tolerated well, enteral nutrition was escalated in the following days. Ventilated patients received a transnasal double-lumen catheter for jejunal feeding and gastric drainage. Effectiveness of the treatment was assessed by the quality of drainage fluids and clinical improvement of the patient. Contrast-enhanced fluoroscopy or computed tomography (CT) was performed if there was any doubt about effective leak closure.

If necessary, additional chest tubes were inserted via mini-thoracotomy or interventional drainages were placed under CT guidance. In the initial period, the stent was removed after 1 week to assess healing of the lesion and exclude stent-related complications, but later the time was extended to approximately 14 days. Complete closure of the leak was confirmed endoscopically and by contrast-enhanced fluoroscopy (Figure 1). If there was evidence of a residual leak, another stent was inserted and the procedure was repeated 10 days later. Except in 1 postoperative case, stenting of tracheoesophageal fistula was considered as a definitive palliative treatment.

\section{Data Analysis}

Clinical data of patients and treatment were entered prospectively in a database. This analysis includes all patients who were treated by stenting. In this group of patients, the exact number of patients who were treated surgically or by stenting is unknown because some of the patients were transferred from other institutions.
Data for assessment of the efficacy of stent treatment included number of stents required, time to oral intake, ventilatory support, time of ICU stay, and time of hospital stay. Complications of stent implantation, such as migration, obstruction, and bleeding, were also recorded. Complete healing of the leak, perforation, and fistula was assessed by esophagogastroscopy, radiography with water-soluble contrast enhancement, and multislice CT scan. All patients enrolled in the study were followed up in 3-month intervals after SEPS removal.

\section{RESULTS}

SEPS were successfully inserted in all 41 patients with esophageal leaks. There was no technical failure in stent placement. Except for stent migration, procedure-related complications were not observed. Usually, it was no problem to reposition the stent endoscopically using a forceps. In case of a leak associated with a stricture, a snare technique was used. The loop of the snare was placed around the proximal end of the stent and tightened. The compressed stent was then gently replaced over the leak.

There was no problem with pain or airway obstruction in patients with proximal or mid-third esophageal stent placement. A single stent was implanted in 27 patients with anastomotic leak $(90 \%)$, 5 patients with esophageal perforation $(83 \%)$, and 3 patients with esophageal fistula $(60 \%)$. Overall repeated stenting was necessary in 38 of 41 patients. In non-ventilated patients, the mean time to oral intake was 3.0 days (range, $0-19$ days).

Complete sealing of the leak immediately after stenting was observed in 25 of 30 patients $(84 \%)$ with anastomotic leakage. In some patients with a gastric conduit $(n=4)$ or colonic conduit $(\mathrm{n}=1)$, there was backflow of contrast around the stent in the reverse Trendelenburg position. These patients were instructed to maintain an upright position as much as possible. Healing of the anastomotic leak without reoperation was achieved in 27 of 30 patients $(90 \%)$. Two patients with mediastinal leaks underwent repeat surgery with anastomotic repair because of persistent leakage despite stent treatment. Both patients subsequently died of persistent sepsis and multiorgan failure. Rethoracotomy was performed in 1 patient with a leak of an esophago-colonic anastomosis because of stent dislocation and inability to place new a stent. A new stent was placed intraoperatively, and the leak healed after 19 days. Stent treatment of perforations was successful in 5 of 6 patients $(83 \%)$. Two patients with esophageal cancer underwent curative esophagectomy after healing of the leak and regeneration. No further treatment was required in 3 patients with benign perforations. One geriatric patient died of severe sepsis resulting from pneumonia and residual mediastinitis.

In the group with fistula, there were 3 patients with advanced esophageal cancer in whom stenting was performed as a definitive palliative treatment. As expected, control bronchoscopy confirmed persistence of the fistula in all 3 patients until they died of progressive disease. However, healing of the fistula was achieved in 2 patients $(40 \%)$. 
TABLE 1. Clinicopathologic characteristics of 41 patients with esophageal leaks, perforations, or fistulae

\begin{tabular}{lccc}
\hline $\begin{array}{c}\text { Patient } \\
\text { characteristics }\end{array}$ & $\begin{array}{c}\text { Anastomotic leak } \\
(\mathbf{n}=\mathbf{3 0})\end{array}$ & $\begin{array}{c}\text { Esophageal } \\
\text { perforation }(\mathbf{n}=\mathbf{6})\end{array}$ & $\begin{array}{c}\text { Esophageal } \\
\text { fistula }(\mathbf{n}=\mathbf{5})\end{array}$ \\
\hline Age, y (range) & $62(50-77)$ & $71(51-90)$ & $57(49-72)$ \\
Gender & & & \\
$\quad$ Male:female & $24: 6$ & $5: 1$ & $3: 2$ \\
Diagnosis & & & \\
Cancer & 29 & 4 & 4 \\
Esophagus* & $17^{*}$ & $2 *$ & 4 \\
EGJ & 6 & 2 & 0 \\
Stomach & 6 & 0 & 0 \\
Benign & $1 \dagger$ & 2 & 1 \\
Tumor type & & & \\
AC & 16 & 2 & 0 \\
SCC & 5 & 0 & 0 \\
GIST & 1 & 1 & 4 \\
\hline
\end{tabular}

$E G J$, Esophago-gastric-junction; $S C C$, squamous cell cancer; $A C$, adenocarcinoma; GIST, gastrointestinal stroma tumor. *Including 1 patient with GIST. †Esophageal diverticulum.

One patient with a tracheo-oesophageal fistula after esophagectomy for esophageal cancer was successfully treated by double stenting of the esophagus and the main bronchus. The other patient had a chronic esophago-pleural fistula after removal of a penetrated gastric band.

The mean time to lesion healing in anastomotic leaks (time to stent retrieval) was 30 days (Table 2). Stent migration was observed in 14 of 41 patients $(35 \%)$. In all but 1 case, stent dislocation could be managed by re-stenting or endoscopic repositioning of the stent. In addition to the stent, perianastomotic or pleural drainage was obtained by CT-guided drainage in 18 patients.
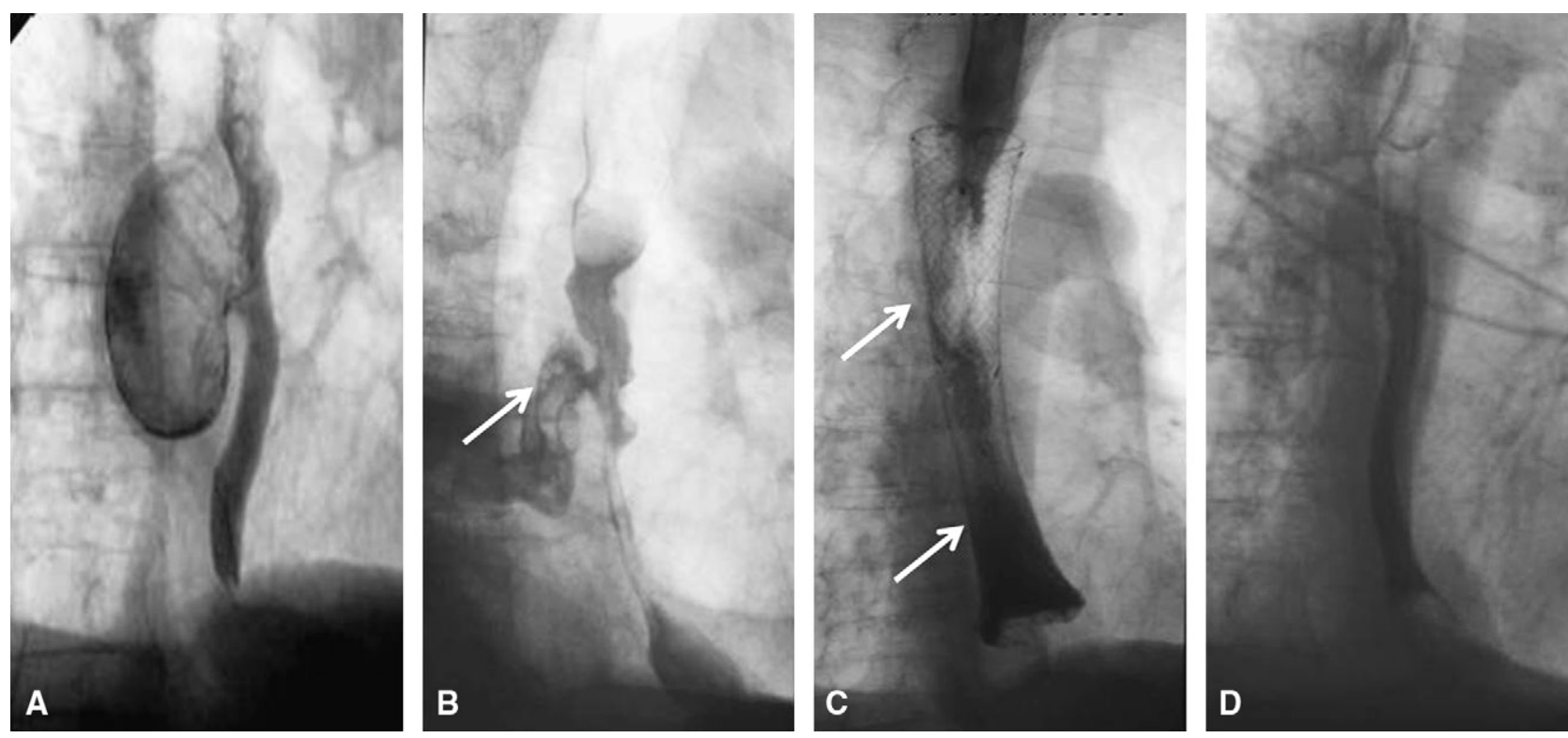

FIGURE 1. Radiogram of a large esophageal diverticulum (A), leakage of the stapler line after thoracoscopic resection of the diverticulum (B), complete closure of the leak by a stent (C), and healing of the leak without stenosis after 27 days of stent treatment (D). 
TABLE 2. Clinical results in $\mathbf{4 1}$ patients after self-expanding plastic stent placement

\begin{tabular}{lccc}
\hline \multicolumn{1}{c}{ Clinical results } & $\begin{array}{c}\text { Anastomotic } \\
\text { leak } \\
(\mathbf{n}=\mathbf{3 0})\end{array}$ & $\begin{array}{c}\text { Esophageal } \\
\text { perforation } \\
(\mathbf{n}=\mathbf{6})\end{array}$ & $\begin{array}{c}\text { Esophageal } \\
\text { fistula } \\
(\mathbf{n}=\mathbf{5})\end{array}$ \\
\hline ICU stay (d) & $21(0-79)$ & $22(0-91)$ & $15(0-63)$ \\
Hospital stay (d) & $45(9-115)$ & $35(9-91)$ & $30(6-63)$ \\
Other therapy & & & \\
$\quad$ Reoperation* & $3(10 \%)$ & $0(0 \%)$ & $0(0 \%)$ \\
$\quad$ Interventional drainage & $12(29 \%)$ & $5(83 \%)$ & $1(20 \%)$ \\
$\quad$ Tracheotomy & $13(32 \%)$ & $1(17 \%)$ & $1(20 \%)$ \\
Time to oral Intake $(\mathrm{d}) \dagger$ & $2.7(0-19)$ & $3.2(1-9)$ & $2.2(1-2)$ \\
Time to leak healing $(\mathrm{d})$ & $30(7-62)$ & $15(6-26)$ & $16(13-19)$ \\
In-hospital mortality & $2(7 \%)$ & $2(17 \%)$ & $0(0 \%)$ \\
\hline
\end{tabular}

$I C U$, Intensive care unit. *For stent failure. $\dagger$ Non-ventilated patients. Values are mean (range or percentage).

the uncovered ends of the stent become deeply embedded in the esophageal wall. ${ }^{18,19}$ Completely covered SEMS and silicone-covered SEPS have been developed to avoid this problem.

The current study evaluated the results of SEPS stenting in a group of 41 patients with esophageal leaks. Complete healing of the leak was achieved in a high rate of patients with anastomotic leakage $(90 \%)$ and esophageal perforation $(83 \%)$ after a mean treatment of 30 days and 15 days, respectively. The mortality in the anastomotic leak group was $7 \%$.

This rate is still higher than the mortality rate of $3.3 \%$ reported in a large series of patients who underwent reoperation with closure of intrathoracic leaks with muscle flaps. ${ }^{19}$ These data demonstrate that reoperation with surgical repair remains a viable option for selective management of esophageal leak in specialized institutions.

In this study, the overall mortality rate after stent treatment of esophageal leaks, perforations, and fistula was $10 \%$. Most of those patients were transferred from other institutions and underwent delayed stenting. Patients died of sepsis despite subsequent rethoracotomy with mediastinal drainage. Immediate stenting after diagnosis of a leak seems to be crucial to avoid further bacterial contamination of the mediastinum. Our data suggest that temporary stenting is effective in the treatment of non-malignant esophageal leaks. Similar results with high healing rates $(80-90 \%)$ and low mortality rates after treatment of anastomotic leaks or esophageal perforations using covered stents have been reported by other groups. ${ }^{20}$ Stent treatment may be not appropriate for extensive leaks, conduit necrosis, or cervical leaks. In this series, there was only 1 patient with a limited conduit necrosis who underwent stenting. Subsequent reoperation with colonic interposition was necessary because of recurrent stenosis. A stenosis requiring endoscopic balloon dilatation developed in 3 patients with cervical leaks.

Langer and colleagues ${ }^{21}$ observed a stenosis of the gastrojejunostomy in 2 of 7 patients after stent retrieval and recommend permanent stenting in patients with gastric pull-up. In this series, stents were removed or changed approximately 14 days after placement. This approach controls healing of the leak and avoids perforations. Frequent stent change, however, may undermine the cost advantages of plastic stents. Although some mucosal ulcerations were observed after 2 weeks, it seems reasonable to extend the time to stent removal further to a mean healing time of 30 days.

One problem with SEPS is the relatively high rate of stent migration. In our study, dislocation of the stent occurred in $35 \%$ of the cases, which is similar to the rates reported from other groups $(10 \%-30 \%))^{22,23}$ The plastic stent is characterized by a smooth surface that favors migration but facilitates retrieval. This situation generally can be managed by removal and exchange of the stent or overstenting. The problem of stent migration and incomplete sealing of big conduits may be solved by stents with larger diameter. In the meantime, a completely covered SEMS with a diameter of $3 \mathrm{~cm}$ has been developed and seems to be promising. ${ }^{24}$

Nonetheless, stenting of anastomotic leaks after gastrectomy should be done with caution because migration of the stent can result in obstructive ileus and reoperation of the patient. This problem was not observed in the current study. One limitation of this study is that the results of stenting are not compared with other treatments because some of the patients were transferred from other institutions. However, a historical comparative study on treatment of esophageal anastomotic leaks has been published. ${ }^{25}$ Intraluminal vacuum sponge therapy is a new method for management of esophageal leaks. ${ }^{26}$ At present, the small number of treated patients does not allow definite assessment of this experimental therapy.

\section{CONCLUSIONS}

The results of this study suggest that a brief period of stenting with self-expanding covered stents is an effective treatment for thoracic esophageal anastomotic leaks and esophageal perforations. Patients with large leaks, conduit necrosis, or cervical anastomosis are better treated surgically. Immediate stenting in combination with adequate surgical drainage can avoid reoperation in selected patients and reduce leak-related morbidity and mortality.

\section{References}

1. Wright CD, Kucharczuk JC, O'Brien SM, Grab JD, Allen MS. Predictors of major morbidity and mortality after esophagectomy for esophageal cancer: a Society of Thoracic Surgeons General Thoracic Surgery Database risk adjustment model. J Thorac Cardiovasc Surg. 2009;137:587-95.

2. Orringer MB, Marshall B, Iannettoni MD. Eliminating the cervical esophagogastric anastomotic leak with a side-to-side stapled anastomosis. J Thorac Cardiovasc Surg. 2000;119:277-88

3. Whooley BP, Law S, Alexandrou A, Murthy SC, Wong J. Critical appraisal of the significance of intrathoracic anastomotic leakage after esophagectomy for cancer. Am J Surg. 2001;181:198-203. 
4. Urschel JD. Esophagogastrostomy anastomotic leaks complicating esophagectomy: a review. Am J Surg. 1995;169:634-40.

5. Sauvanet A, Baltar J, Le Mee J, Belghiti J. Diagnosis and conservative management of intrathoracic leakage after oesophagectomy. Br J Surg. 1998;85:1446-9.

6. Adam DJ, Thompson AM, Walker WS, Cameron EW. Oesophagectomy for iatrogenic perforation of esophageal and cardia carcinoma. Br J Surg. 1996; 83:1429-32.

7. Heitmiller RF, MCQuone SJ, Eisele DW. The utility of the pectoralis myocutaneous flap in the management of select cervical esophageal anastomotic complications. J Thorac Cardiovasc Surg. 1998;115:1250-4.

8. Crestellano JA, Deschamps C, Cassivi SD, Nichols FC, Allenn MS, Schleck C, et al. Selective management of intrathoracic leak after esophagectomy. J Thorac Cardiovasc Surg. 2005; 129:254-60.

9. Brown TH, Nicholson DA, Irving MH, Bancewicz J. Use of a self expanding metal stent for oesophagogastric fistulation. Br J Surg. 1995;82:663-4.

10. May A, Ell C. Palliative treatment of malignant esophagorespiratory fistulas with Gianturco-Z stents. A prospective clinical trial and review of the literature on covered metal stents. Am J Gastroenterol. 1998;93:532-5.

11. Dai YY, Gretschel S, Dudeck O, Rau B, Schlag PM, Hünerbein M. Treatment of oesophageal anastomotic leaks by temporary stenting with self expanding plastic stents. Br J Surg. 2009;96:887-91.

12. Orringer MB, Lemmer JH. Early dilatation in the treatment of esophageal disruption. Ann Thorac Surg. 1986;42:536-9.

13. Pennathur A, Chang AC, McGrath KM, Steiner G, Alvelo-Rivera M, Awais O, et al. Polyflex expandable stents in the treatment of esophageal disease: initial experience. Ann Thorac Surg. 2008;85:1968-72.

14. Bethge N, Sommer A, Vakil N. Treatment of esophageal fistulas with a new polyurethane-covered, self-expanding mesh stent: a prospective study. Am J Gastroenterol. 1995;90:2143-6.

15. Cook TA, Dehn TC. Use of covered expandable metal stents in the treatment of esophageal carcinoma and tracheo-oesophageal fistula. Br J Surg. 1996;83: 1417-8.
16. Roy-Choudhury SH, Nicholson AA, Wedgwood KR, Mannion RA, Sedman PC Royston CM, et al. Symptomatic malignant gastroesophageal anastomotic leak: management with covered metallic esophageal stents. AJR Am J Roentgenol. 2001;176:161-5.

17. Evrard S, Le Moine O, Lazaraki G, Dormann A, El Nakadi I, Devière J. Self-expanding plastic stents for benign esophageal lesions. Gastrointest Endosc. 2004; 60:894-900

18. Siersema PD. Treatment of esophageal perforations and anastomotic leaks: the endoscopist is stepping into the arena. Gastrointest Endosc. 2005;61: 897-900.

19. Martin LW, Swisher SG, Hofstetter W, Correa AM, Mehran RJ, Rice DC, et al Intrathoracic leaks following esophagectomy are no longer associated with increased mortality. Ann Surg. 2005;242:392-9.

20. Freeman RK, Ascioti AJ, Wozniak TC. Postoperative leak management with the Polyflex esophageal stent. J Thorac Cardiovasc Surg. 2007;133:333-8.

21. Langer FB, Wenzl E, Prager G, Salat A, Miholic J, Mang T, et al. Management of postoperative esophageal leaks with the Polyflex self-expanding covered plastic stent. Ann Thorac Surg. 2005;79:398-403.

22. Radecke K, Lang H, Frilling A, Gerken G, Treichel U. Successful sealing of benign esophageal leaks after temporary placement of a self-expanding plastic stent without fluoroscopic guidance. Z Gastroenterol. 2006;44:1031-8.

23. Conigliaro R, Battaglia G, Repici A, De Pretis G, Ghezzo L, Bittinger M, et al Polyflex stents for malignant oesophageal and oesophagogastric stricture: a prospective, multicentric study. Eur J Gastroenterol Hepatol. 2007;19:195-203.

24. Zehetner J, Shamiyeh A, Wayand W, Hubmann R. Results of a new method to stop acute bleeding from esophageal varices: implantation of a self expanding stent. Surg Endosc. 2008;22:2149-52.

25. Hünerbein M, Stroszczynski C, Moesta KT, Schlag PM. Treatment of anastomotic leaks after esophagectomy with self expanding plastic stents. Ann Surg. 2004;240:801-7.

26. Loske G, Schorsch T, Müller C. Endoscopic vacuum sponge therapy for esophageal defects. Surg Endosc. 2010;24:2531-5. Epub 2010 Mar 24. 